\title{
A Curious Case of Hypercalcemia
}

By Douglas Ian Noboru Motomura MD, and Paul Allan Cameron MD, and Nabha Shetty MD

DOI :10.22374/cjgim.v13i1.216

\begin{abstract}
About the Authors
Douglas Motomura, Paul Cameron, and Nabha Shetty are all with Dalhousie University, Halifax, Nova Scotia. Submitted: June 6, 2017; Accepted: August 15, 2017. Published: March 5, 2018.
\end{abstract}

\begin{abstract}
Hypercalcemia is a clinical entity commonly seen on Internal Medicine inpatient units. Through standard diagnostic algorithms, the etiology of most cases can be elucidated. Brivaracetam is a novel anti-epileptic agent that binds synaptic vesicle protein $2 \mathrm{~A}$ shown to significantly reduce seizure frequency. We describe the first case of hypercalcemia secondary to brivaracetam.

\section{Résumé}

L'hypercalcémie est un syndrome clinique observé fréquemment en médecine interne chez les patients hospitalisés. Au moyen d'algorithmes de diagnostic standard, l'étiologie de la plupart des cas peut être élucidée. Le brivaracetam est un nouvel antiépileptique qui se lie à la protéine $2 \mathrm{~A}$ des vésicules synaptiques et réduit de manière importante la fréquence des convulsions. Nous décrivons le premier cas d'hypercalcémie secondaire consécutive au brivaracetam.
\end{abstract}

A 53-year-old male with medically refractory epilepsy, diabetes mellitus and pancytopenia secondary to anti-epileptic medications presented to hospital with fatigue and constipation. Investigations revealed creatinine of $390 \mathrm{umol} / \mathrm{L}$ (baseline $110 \mathrm{umol} / \mathrm{L}$ ) and an uncorrected calcium of $3.6 \mathrm{mmol} / \mathrm{L}$. Serum parathyroid hormone level was 1.6, serum protein electrophoresis did not reveal a monoclonal band and urine calcium was elevated. Computed tomography of his chest abdomen and pelvis did not show malignancy or granulomatous lesions. Positron emission tomography was negative. A bone marrow biopsy showed trilineage hematopoiesis with no features of malignancy. PTH-rp levels were undetectable. Fourteen days after drug cessation, intravenous fluid resuscitation and treatment with pamidronate as well as calcitonin, his calcium normalized. Investigation results are summarized in Table 1.

Excluding all other potential aetiologies of hypercalcemia and clinical as well as biochemical improvement following withdrawal of the drug brivaracetam was felt to be the causative agent. This case demonstrates the ability of brivaracetam to cause symptomatic severe hypercalcemia and emphasizes the need for care providers to monitor calcium while on therapy.

\section{Case Presentation}

A 53-year-old man, originally from Finland but raised in Halifax, Nova Scotia presented to the emergency department after an elevated creatinine was found by a walk-in clinic physician. He had a medical history of a seizure disorder without clear etiology, despite extensive workup. He suffered from 1-2 generalized tonicclonic seizures per month on average, which were refractory to medical management. He also had well-controlled type 2 diabetes that is well controlled, and a chronic, mild pancytopenia.

For his seizures, he had not tried multiple combinations of anti-epileptics and in August of 2016, started a novel antiepileptic called Brivlera (brivaracetam), which is a relative of Keppra (levitiracetam). This new anti-epileptic was only recently approved for usage in Canada in March of 2016. It was initially tolerated to good effect, and at the time of presentation he had not had any seizure activity since starting the medication. His other medications included lamotrigine, divalproex and metformin.

In mid September 2016, he began to feel generally unwell. He had decreased appetite, worsening weakness, headaches, constipation, and nausea. He was given a requisition for bloodwork which showed a significant kidney injury. Creatinine was 390 


\begin{tabular}{|lll}
\hline \multicolumn{1}{|c}{ Investigations } & \multicolumn{1}{c}{ Value } & \multicolumn{1}{c}{ Reference } \\
\hline Creatinine & $390 \mathrm{umol} / \mathrm{L}$ & $64-104 \mathrm{umol} / \mathrm{L}$ \\
\hline Urea & $21.3 \mathrm{mmol} / \mathrm{L}$ & $2.5-9.2 \mathrm{mmol} / \mathrm{L}$ \\
\hline Sodium & $134 \mathrm{mmol} / \mathrm{L}$ & $136-145 \mathrm{mmol} / \mathrm{L}$ \\
\hline Potassium & $5.4 \mathrm{mmol} / \mathrm{L}$ & $3.4-5.0 \mathrm{mmol} / \mathrm{L}$ \\
\hline Total CO & $26 \mathrm{mmol} / \mathrm{L}$ & $22-31 \mathrm{mmol} / \mathrm{L}$ \\
\hline WBC & $5.82 \times 10^{9} / \mathrm{L}$ & $4.5-11 \times 10^{9} / \mathrm{L}$ \\
\hline Platelet Count & $125 \times 10^{9} / \mathrm{L}$ & $150-350 \times 10^{9} / \mathrm{L}$ \\
\hline Hemoglobin & $121 \mathrm{~g} / \mathrm{L}$ & $140-180 \mathrm{~g} / \mathrm{L}$ \\
\hline Albumin & $27 \mathrm{~g} / \mathrm{L}$ & $35-50 \mathrm{~g} / \mathrm{L}$ \\
\hline Calcium & $3.60 \mathrm{mmol} / \mathrm{L}$ & $2.20-2.60 \mathrm{mmol} / \mathrm{L}$ \\
\hline Magnesium & $1.27 \mathrm{mmol} / \mathrm{L}$ & $0.66-1.07 \mathrm{mmol} / \mathrm{L}$ \\
\hline Phosphorus & $1.85 \mathrm{mmol} / \mathrm{L}$ & $0.74-1.52 \mathrm{mmol} / \mathrm{L}$ \\
\hline PTH & $1.6 \mathrm{pmol} / \mathrm{L}$ & $1.9-8.7 \mathrm{pmol} / \mathrm{L}$ \\
\hline 25-OH-Vitamin D & $61.4 \mathrm{nmol} / \mathrm{L}$ & $25-75 \mathrm{nmol} / \mathrm{L}$ \\
\hline 1,25-OH-Vitamin D & $107 \mathrm{pmol} / \mathrm{L}$ & $48-190 \mathrm{pmol} / \mathrm{L}$ \\
\hline Free Kappa & $50.26 \mathrm{mg} / \mathrm{L}$ & $3.3-19.4 \mathrm{mg} / \mathrm{L}$ \\
\hline Free Lambda & $27.75 \mathrm{mg} / \mathrm{L}$ & $5.71-26.30 \mathrm{mg} / \mathrm{L}$ \\
\hline Free Kappa/Lambda ratio & 1.81 & $0.26-1.65$ \\
\hline T4 & $8.9 \mathrm{pmol} / \mathrm{L}$ & $9.0-19.0 \mathrm{pmol} / \mathrm{L}$ \\
\hline Valproic Acid & $636 \mathrm{umol} / \mathrm{L}$ & $350-700 \mathrm{umol} / \mathrm{L}$ \\
\hline 24h Urine Calcium & $11.6 \mathrm{mmol} / \mathrm{TV}$ & $0-7.4 \mathrm{mmol} / \mathrm{TV}$ \\
\hline PTrine Creatinine & $7.9 \mathrm{mmol} / \mathrm{TV}$ & $8.4-22.0 \mathrm{mmol} / \mathrm{TV}$ \\
\hline
\end{tabular}

PTH = parathyroid hormone; PTHrp = parathyroid hormone-related protein; WBC = white blood cell count.

umol/L from a baseline near $110 \mathrm{umol} / \mathrm{L}$, thus was asked to go to the emergency department.

Due to the suspicious timing, brivaracetam was held on admission. His other anti-epileptics were continued throughout his stay in hospital. His metformin was held due to his kidney injury as well.
On assessment the patient looked generally volume deplete. His jugular venous pressure was not visible. His mucous membranes were dry. There was no abdominal pain or costovertebral angle tenderness. Neurologic exam was normal.

Workup for the acute kidney injury began. Urinalysis was bland and free of blood, protein, bacteria or leukocytes. Extended electrolytes were ordered and revealed a calcium level of 3.60 $\mathrm{mmol} / \mathrm{L}$ and corrected with the patient's albumin of $27 \mathrm{~g} / \mathrm{L}$, was $3.86 \mathrm{mmol} / \mathrm{L}$. The patient was admitted for treatment of hypercalcemia.

\section{Investigations}

Following the diagnosis of hypercalcemia, a thorough history regarding potential etiology was undertaken.

No clinical causes were identified except the possibility of it being a medication side effect given the recent initiation of brivaracetam.

The first blood test ordered was parathyroid hormone (PTH) level, which was appropriately low at $1.6 \mathrm{pmol} / \mathrm{L}$. Familial hypocalcuric hypercalcemia, was ruled out by a 24 -hour urine calcium showing an appropriately high level of $9.0 \mathrm{mmol} / \mathrm{TV}$. Vitamin D levels were normal, suggesting no exogenous vitamin D supplementation driving his hypercalcemia.

Because of the combination of anemia and pancytopenia along with hypercalcemia, a pan CT was ordered to assess for lymphoma or other malignancies, but no significant abnormalities were detected. A PET scan was done to assess for granulomatous disease. The only uptake seen was in the gluteal muscles, reported to represent calcyphlaxis, a condition most commonly (though not exclusively) associated with longstanding dialysis. These deposits were not palpable clinically and could not be biopsied (Figure 1).

Multiple myeloma was also a diagnostic consideration. SPEP did not show a monoclonal band. Serum free light chains were minimally elevated, but in consultation with hematology, deemed not to be in keeping with multiple myleoma. Regardless, as no other clear etiology emerged, bone marrow biopsy was performed, showing normal trilineage hematopoiesis and no increase in plasma cells.

After discharge from hospital, the PTH-related peptide and 1,25-OH-Vitamin D levels returned from outside labs, both normal, making a neoplastic process or granulomatous process even less likely.

\section{Treatment}

The initial management of his hypercalcemia consisted of aggressive fluid rehydration with normal saline, more than 7 litres over the first 48 hours. Furosemide was later started to help maintain euvolemia, as well as for its minor affects on calcium 


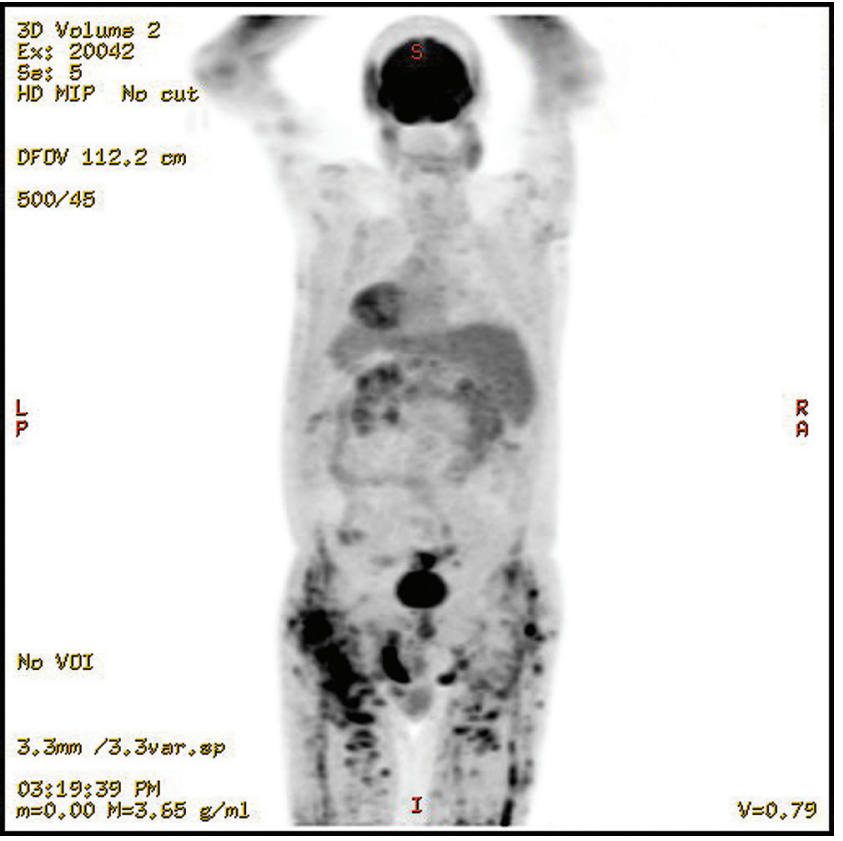

Figure 1. PET CT showing uptake in the gluteal region.

secretion. Pamidronate was administered twice, one week apart, to block calcium resorption from bone.

Calcitonin was started several days following admission and was increased two days later. It was discontinued shortly thereafter for suspected tachyphylaxis. Figure 2 demonstrates the response of the calcium and creatinine to the previously mentioned interventions.
Finally, the utility of empiric steroids was discussed. At the time of consideration the $1,25-\mathrm{OH}-\mathrm{Vitamin} \mathrm{D}$ levels were pending, but there was no evidence of any granulomatous disease. The pros and cons of empiric treatment were discussed with the endocrinology, hematology and nephrology consult team. The consensus decision was to avoid a trial of steroids until more substantial evidence of potential benefit was produced.

\section{Outcome}

Upon discharge from hospital, the patient's renal function slowly improved and his calcium remained stable with only oral hydration. At 6-months post discharge he was seen in general medicine follow-up clinic, and his creatinine had stabilized at $125 \mathrm{umol} / \mathrm{L}$, with a normal ionized calcium at $1.26 \mathrm{mmol} / \mathrm{L}$.

He was also reassessed by his neurology team. It was stated that following discharge from the hospital, the patient quickly suffered 3 general tonic clonic seizures, indicating loss of the previously achieved anti-epileptic control. The decision was made to not restart the brivaracetam unless a clear etiology of the hypercalcemia was found. Instead, a trial of topiramate was initiated.

He was seen in follow up by the nephrology service. It was felt that his residual kidney injury was most likely secondary to the episode of hypercalcemia, and not a primary kidney process. No nephrology follow-up was indicated.

\section{Discussion}

Brivaracetam is primarily an SV2A (Synaptic vesicle protein 2A) ligand, similar to levetiracetam (keppra). ${ }^{1}$ Though the

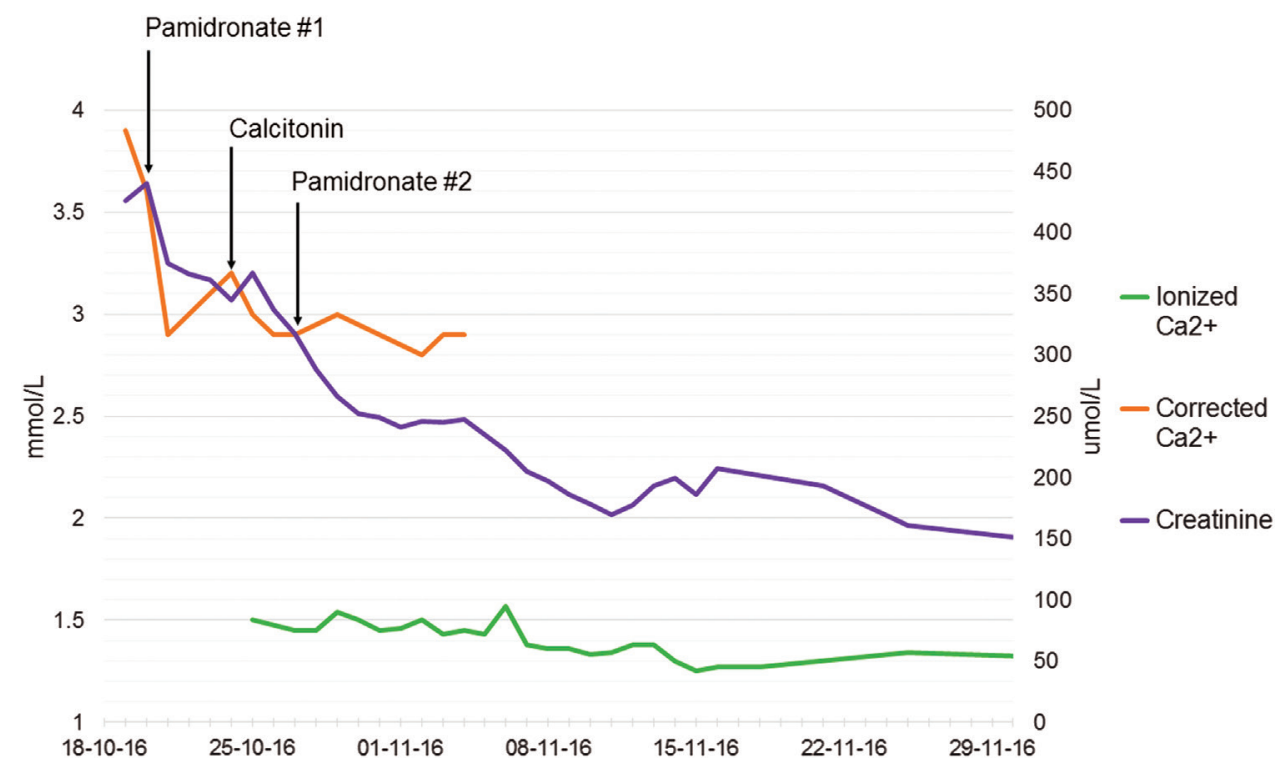

Figure 2. Response of the calcium and creatinine to the previously mentioned interventions. 
exact physiologic mechanism is unknown, robust randomized control trial evidence shows that brivaracetam dosing twice daily significantly reduces the frequency of seizures versus placebo. ${ }^{2}$ Interestingly, the binding affinity of Brivaracetam is reported to be over 30 times that of Keppra.

Brivaracetam was recently approved for usage in Canada in March of $2016^{3}$ and in the United States as of February 18th 2016. ${ }^{4}$ Hypercalcemia was not a reported side effect in the clinical trial data (total participants over 1500). Moreover, hypercalemia is not a reported side effect of levetiracetam, whose mechanism is well understood. ${ }^{5}$

However, extensive investigations into other possible causes of the patient's hypercalcemia remained fruitless. This fact, combined with the timing coinciding with the initiation of Brivera, the gradual improvement following the discontinuation of the drug, and the lack of relapse following discharge seem to provide strong evidence of a causative effect from the drug. If so, this would be the first reported case in the literature. It is interesting to note that when the drug manufacturer was directly contacted, they had two other reports of hypercalcemia in the United States. There were no other reports from Canada. Further monitoring will be required as more patients begin to use this novel antiepileptic medication

Consent was obtained from the patient's substitute decision maker on Jan 19th - 2017.

\section{Learning Points}

- This case describes a unique side effect of a novel antiepileptic drug, not previously reported in the literature.

- This case summarizes a thorough workup of the various etiologies of hypercalcemia.

- This case provides an overview of the standard treatments for refractory for hypercalcemia, as well as monitoring of the response to treatment.

\section{References}

1. Pack, Alison M. "Brivaracetam, a Novel Antiepileptic Drug: Is It Effective and Safe? Results from One Phase III Randomized Trial." Epilepsy Currents 14.4 (2014): 196-98. Web. https://www.ncbi.nlm.nih.gov/pmc/articles/ PMC4120388/

2. Biton, Victor, et al. Brivaracetam as Adjunctive Treatment for Uncontrolled Partial Epilepsy in Adults: A Phase III Randomized, Double-blind, Placebocontrolled Trial." Epilepsia 55.1 (2013): 57-66. Web. https://www.ncbi.nlm.nih gov/pubmed/24446953

3. "Summary Basis of Decision (SBD) - Brivlera." Health Canada, n.d. Web. 09 Apr. 2017. http://www.hc-sc.gc.ca/dhp-mps/prodpharma/sbd-smd/indexeng.php

4. Commissioner, Office Of the. "Press Announcements - FDA Approves Briviact to Treat Partial Onset Seizures." U S Food and Drug Administration Home Page. Office of the Commissioner, n.d. Web. 09 Apr. 2017. https://www. fda.gov/newsevents/newsroom/pressannouncements/ucm486827.htm

5. Aksoy, Duygu et al. "Effects of Oxcarbazepine and Levetiracetam on Calcium, Ionized Calcium, and 25-OH Vitamin-D3 Levels in Patients with Epilepsy." Clinical Psychopharmacology and Neuroscience 14.1 (2016): 74-78. Web. https://www.ncbi.nlm.nih.gov/pmc/articles/PMC4730931/ 